\title{
Ureteroscopic biopsy of upper tract urothelial carcinoma and role of urinary biomarkers
}

\author{
Katherine E. Smentkowski, Demetrius H. Bagley, Scott G. Hubosky \\ Department of Urology Sidney Kimmel Medical College, Thomas Jefferson University Hospital, Philadelphia, PA, USA \\ Contributions: (I) Conception and design: SG Hubosky; (II) Administrative support: SG Hubosky; (III) Provision of study materials or patients: KE \\ Smentkowski; (IV) Collection and assembly of data: KE Smentkowski, SG Hubosky; (V) Data analysis and interpretation: KE Smentkowski, SG \\ Hubosky; (VI) Manuscript writing: All authors; (VII) Final approval of manuscript: All authors. \\ Correspondence to: Scott Gabriel Hubosky. Department of Urology Sidney Kimmel Medical College, Thomas Jefferson University Hospital, \\ Philadelphia, PA, USA. Email: Scott.hubosky@jefferson.edu.
}

\begin{abstract}
Ureteroscopic biopsy is an integral part of diagnosis of urothelial carcinoma of the upper urinary tract. It can be a technical challenge, but diagnostic rates have improved remarkably with refinements in surgical technique and specimen processing. Cytology aids with diagnosis and other urinary biomarkers continue to evolve, which may help further stratify patients for treatment. The current literature on the ureteroscopic biopsy and role of urinary biomarkers is reviewed and summarized below.
\end{abstract}

Keywords: Upper tract urothelial carcinoma (UTUC); ureteroscopy; biopsy; urinary biomarker

Submitted Oct 15, 2019. Accepted for publication Nov 18, 2019.

doi: 10.21037/tau.2019.11.28

View this article at: http://dx.doi.org/10.21037/tau.2019.11.28

\section{Introduction}

Significant advancements have been made in the last 30 years in the diagnosis of upper tract urothelial carcinoma (UTUC), but certain aspects still remain a challenge for the clinician. Computerized tomographic urography (CTU) has made great strides in aiding the diagnosis of urothelial malignancies with $88-100 \%$ sensitivity and $93-100 \%$ specificity on meta-analysis (1). Additionally, it can detect filling defects as small as $5 \mathrm{~mm}$ (2). A major barrier is that imaging alone fails to provide tissue diagnosis to guide further treatment. It therefore remains part of the workup, rather than a means for definitive diagnosis. Repeated radiation exposure also remains a concern (1).

Currently, ureteroscopy with biopsy is the cornerstone of initial diagnosis and ongoing surveillance $(3,4)$. Using our method of diagnosis and specimen handling, we have achieved a $97.2 \%$ success rate in grading biopsy specimens, mainly by changing the way we process specimens (5). Despite this, ureteroscopy also has its limitations, which will be described herein.

All of the above highlight the need for the development of a non-invasive means for diagnosis. The role of urinary biomarkers has been an interest of study as a method to aid diagnosis and surveillance after treatment without need for radiation or ureteroscopy and general anesthesia. Cytology is the most widely utilized. Improved diagnostic correlation has recently been suggested with introduction of the Paris System for urine cytology $(6,7)$. Other options, such as FISH have been discussed previously. Currently the detection of DNA mutations and methylation markers in voided urine has gained some popularity in the literature, and preliminary analysis shows promise as a biomarker in the detection of UTUC.

\section{Methods}

A literature review was performed by searching PubMed and Google Scholar using relevant keywords. Results were screened for pertinent publications, with a focus placed on publications from the last 10 years. Further references were obtained from the citations of these papers, as well as guidelines and textbooks. 


\section{Ureteroscopic biopsy}

We have reported notable success with ureteroscopic biopsy as described above, and other studies have reported similar success with a sensitivity and specificity of $83 \%$ and $100 \%$ respectively (8). Arguments have been made for the avoidance of ureteroscopy and biopsy in cases of positive urine cytology and an obvious lesion on CTU when the added diagnostic benefit will not affect management (9). However, in many cases, the outcome of ureteroscopy and biopsy will direct potential neoadjuvant chemotherapy or nephron-sparing treatments and is therefore beneficial. Below we describe our method of ureteroscopic biopsy $(10,11)$.

\section{Initial approach and surveillance}

Evaluation for upper tract urothelial cancer should always begin with thorough cystoscopy of the bladder to rule out concomitant bladder tumors. Urine cytology from the bladder is then obtained and bilateral retrograde pyelograms are performed with great care to avoid excessive back pressure and extravasation. Retrograde pyelogram sets the stage for what to expect. The index of suspicion for encountering an upper tract lesion will be high if a filling defect or stricture is demonstrated.

Ureteroscopic examination of the affected side commences with "no touch" technique. Via this method, manipulation of the urothelium is minimized as not to induce mucosal trauma or bleeding, which could impair detection of subtle lesions. Traditionally, a small semi-rigid ureteroscope is used to examine the distal ureter under direct vision. No wire is passed prior to ureteroscopy and the ureteral orifice is ideally entered without the use of dilation. The ureteroscope is then passed as proximally as possible and replaced with a guidewire, which is not advanced beyond the proximal extent of ureteroscopic examination. The smallest flexible ureteroscope available is then passed over the wire to this point. The remainder of the ureter is examined, and complete ureterorenoscopy is performed in a systematic manner from the upper pole to lower pole, to ensure direct examination of all the potential space of the intraluminal collecting system. If ureteral tumors are encountered during initial ureteroscopy, these are biopsied and treated at the time of discovery. Performance of upper urinary tract surveillance with the exclusive use of flexible ureteroscopy is now possible with the development of optimal distal shaft durometer (shaft stiffness), making semi-rigid instruments necessary in only about half of all cases (12).

\section{Biopsy technique}

When a lesion is encountered, cytology washings are taken via the irrigation channel of the ureteroscope. Then biopsy can be performed using a variety of methods, including $3-\mathrm{F}$ cold cup forceps (Piranha), 6-F back loading biopsy forceps (BIGopsy), or ureteroscopic basket. Several studies have compared these options and noted a 74.9-79\% diagnostic rate for 3-F cold cup forceps, 81.9-90\% for BIGopsy and $87-100 \%$ when using a $2.2-\mathrm{F}$ or $2.4-\mathrm{F}$ wire basket $(13,14)$. In our practice, we favor $3-\mathrm{F}$ cold cup forceps or a $2.4-\mathrm{F}$ stainless steel FlatWire basket (Figure 1). We find BIGopsy forceps impractical due to its back loading nature, tendency to obscure the field of view, and its severe limitations on ureteroscopic deflection (15). Our choice of cold cup forceps versus basket depends on the nature of the lesion; with the cold cup biopsy forceps being superior for sessile lesions, while the stainless steel basket is useful for large friable tumors. We have found that when suitable, the FlatWire basket obtains superior diagnostic results (16). Relatively large volumes of tumor can be sampled (Figure 2). It is the opinion of the authors that stainless steel FlatWire baskets are superior to nitinol baskets for luminal tissue biopsy. Relative to the round, soft wires which comprise nitinol baskets, the flat wires of the stainless steel basket are more rigid and superior in grasping and holding tissue in the angle between the wires with flat edges, allowing for better tissue sampling.

Once the biopsy is obtained, the tumor sample, biopsy device and ureteroscope are removed together as one unit, in order to avoid shearing and loss of the sample. Following this, aspiration for cytology is repeated. If the lesion is endoscopically treated, a final cytology is taken following treatment.

\section{Specimen processing}

All specimens in our practice are sent to cytopathology and processed using the Cytospin technique (10). Any viable tissue is prepared using a cell block. We developed this method as we found that ureteroscopy specimens processed as traditional histological specimens were destroyed during processing. By sending these tumor samples as cytology, diagnostic yield improved from $42.9 \%$ to $97.2 \%$ (5). Similarly, when Vashistha et al. examined the accuracy of 


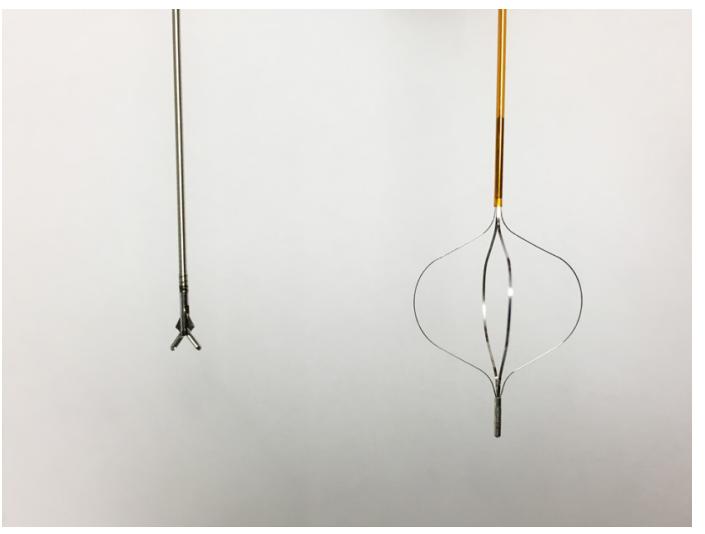

Figure 1 Instruments for ureteroscopic biopsy of upper tract urothelial carcinoma: 3-F cup biopsy forceps (left) and 2.4-F stainless steel flatwire basket.

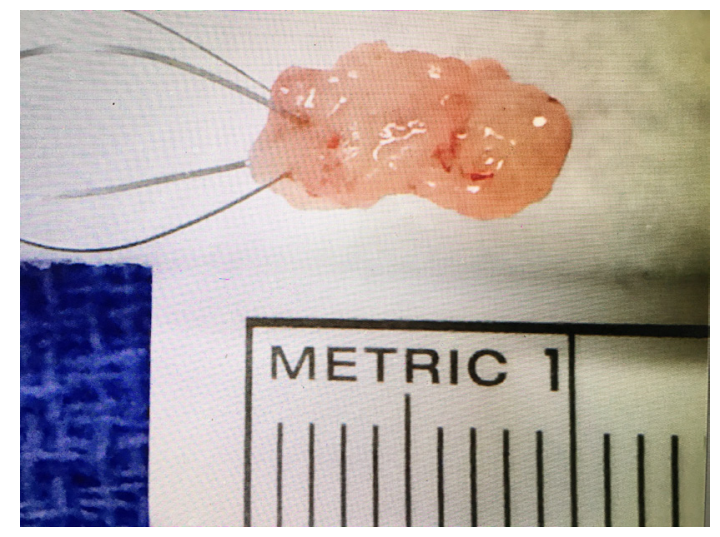

Figure 2 Relatively large luminal tissue samples can be obtained with good endoscopic visualization and preservation of flexible ureteroscope deflection using the 2.4-F stainless steel FlatWire basket. Note the tumor tissue caught in the notch between the flat wires.

ureteroscopy biopsy in 118 samples, specificity was $100 \%$ and sensitivity was $83.0 \%$ (8). Specimen processing was not overtly addressed, however it was implied that biopsies underwent traditional histological preparation.

\section{Limitations}

Despite these successes, ureteroscopic biopsy still remains an imperfect technique in that staging is notoriously inaccurate. Despite the aforementioned specificity and sensitivity, Vashistha found disappointing stage concordance between biopsy specimen and final pathology of 58.6\% (8).
Therefore, tumor grade remains the guiding force in treatment decisions $(3,4)$.

Given these limitations, efforts have been made to identify patients at risk for muscle invasive disease. Margolin et al. found that patients with clinical high grade tumors on ureteroscopic biopsy were found to have a $60 \%$ positive predictive value (PPV) for muscle invasion. If subepithelial tissue was captured on biopsy and was positive, this increased the PPV to $86 \%$ (17).

Other avenues of diagnosis have been explored, such as percutaneous biopsy. In a study looking at 26 patients who underwent percutaneous biopsy for a variety of indications (nondiagnostic URS, prior cystectomy or poor surgical candidate), successful diagnosis of urothelial carcinoma was made in $85 \%$ of cases. However similar to ureteroscopic biopsy, the ability for staging remains limited. In the same study, 14/24 patients had grade information available and $86 \%$ demonstrated concordance with final pathology. Despite diagnostic rates that are comparable to URS and biopsy, percutaneous access comes with the risk of tumor seeding. In the aforementioned study, $13 \%$ of patients demonstrated local recurrence. However, this was determined as unrelated to biopsy as the tumor recurrence was outside of the needle tract. There is, however, literature that supports the risk of tumor seeding, predominantly with percutaneous resection and laparoscopic intervention (18).

\section{Urinary biomarkers}

The use of urinary biomarkers is an invaluable adjunct to diagnosis, with cytology being the most popular, despite its flaws. Cytology does not always provide a clear diagnostic picture, and often times ureteroscopy is needed to further characterize a lesion prior to intervention, which results in several issues. Firstly, not only is ureteroscopy often needed for initial diagnosis, but if a lesion is found, it may subject patients to a need for repeated ureteroscopic surveillance. This results in increased fluoroscopic exposure as well as repeated general anesthesia. Secondly, data has remained mixed on whether diagnostic URS increases the risk of intravesical recurrence of urothelial carcinoma $(19,20)$. A meta-analysis by Guo et al., which looked at 8 studies including 3975 patients, found that those who undergo diagnostic URS are at higher risk of intravesical recurrence however this did not negatively impact survival parameters (21). The field of biomarker development for diagnosis and monitoring therefore remains a continued area of interest. 
Table 1 Diagnostic categories described by the Paris system

Nondiagnostic/unsatisfactory

Negative for high-grade urothelial carcinoma (NHGUC)

Atypical urothelial cells (AUC)

Suspicious for high-grade urothelial carcinoma (SHGUC)

High-grade urothelial carcinoma (HGUC)

Low-grade urothelial neoplasm (LGUN)

Other: primary and secondary malignancies and

miscellaneous lesions

\section{Cytology}

Although cytology remains a gold standard diagnostic tool for UTUC, voided cytology is notoriously inaccurate, with false negative rates of $50-89 \%(22,23)$. Selective cytology has demonstrated greater diagnostic accuracy with metaanalysis revealing a $53.1 \%$ sensitivity with $90 \%$ specificity based on biopsy. Sensitivity is highest for high grade at $70 \%$ but notably lower for low grade (46\%). Part of this ambiguity arises from the great variability in how cellular "atypia" is characterized and the notoriously poor inter-and intraobserver agreement in grading urine cytology $(22,24)$.

To solve the latter problem, new methods of cytologic grading have been developed. The "Paris System" was first described in the literature in 2016 as a new classification method that uses specific criteria in an effort to increase diagnostic accuracy and focuses mainly on high grade diagnosis (24). Table 1 describes the different categories set forth by this system. Studies have shown a 71-78.6\% sensitivity and $86-100 \%$ specificity rate and an almost double rate of surgical concordance when compared with traditional cytology in upper tract disease $(63 \%$ compared to $34 \%)(6,7,25)$. The false negative rate was reported as $7 \%$ and attributed to sampling errors, compared to historical rates of $26 \%$ (6). McIntire et al. also found that implementing the Paris System decreased equivocal or atypical diagnoses by $55 \%$. However, Xing et al., as well as Simon et al., reported a decrease in sensitivity when compared to traditional cytology $(7,25,26)$. Therefore, controversy still remains, as does the ongoing issue of detecting low grade disease.

\section{Fluorescence in situ bybridization testing (FISH)}

FISH testing uses fluorescent probes to detect abnormalities in chromosomes 3, 7, 17 and 9p21 (27). While popular as an adjunct to bladder cancer diagnosis, efforts have been made to apply FISH to UTUC with inconsistent results. When applied to voided urine without concomitant bladder tumor, sensitivity and specificity has varied widely, and reported at $54-76.7 \%$ and $78-94.7 \%$ respectively $(28,29)$.

\section{DNA methylation biomarkers}

The role of epigenetic changes in cancer has been increasingly recognized. Based off tissue immunology, the methylation status of multiple genes has been shown to be associated with UTUC and this work has been extrapolated to the development of urinary biomarkers. Two studies looked at the diagnosis of UTUC by examining voided samples for GDF15, TMEFF2 and VIM promoter methylation status. Monteiro-Reis et al. looked at 22 patients with known UTUC and found that this panel detected UTUC with $91 \%$ sensitivity. UTUC samples demonstrated a significantly higher degree of methylation and this was used to calibrate levels to controls, resulting in a specificity of $100 \%$. Furthermore, VIM methylation status independently was associated with stage and low VIM methylation levels were associated with poor diseasespecific survival. It should be noted that only 3 patients had low grade UTUC and no analysis was performed to look at accuracy of diagnosis in these samples (30). Similarly, Guo et al examined a similar panel, with the addition of genes CDH1, HSPA2 and RASSF1A with a notably lower sensitivity of $82 \%$ and specificity of $68 \%$. Neither of these studies examined whether methylation could distinguish between lower and upper tract lesions (31).

\section{Gene mutation biomarkers}

Several gene mutations have been associated with urothelial carcinoma, and efforts have been made to identify urinary assays that would identify these abnormalities. Hotspot mutations in telomerase reverse transcriptase (TERT) have been investigated as a possible target as well as FGFR3. When examining TERT and FGFR3 mutations in conjunction with cytology had a sensitivity of $78.6 \%$ and specificity of $96 \%$ (32).

\section{Miscellaneous}

Other tumor markers have been described for upper tract 
detection over the past 20 years such as the BTA stat test, FDP test, nuclear matrix protein 22 (NMP 22), and ImmunoCyt (11). Despite sometimes promising results, they have failed to achieve mainstream or guideline endorsed use.

\section{Conclusions}

Ureteroscopy with biopsy in conjunction with urinary markers has greatly increased our ability to detect and diagnose UTUC, however barriers remain. Great strides have been made with the improvement in endoscopic techniques for UTUC diagnosis and specimen handling which have improved diagnostic accuracy. There is an ongoing challenge in the use of urinary cytology, but with improvements and standardization in specimen interpretation, this may improve. Similarly, the role of DNA markers in the role of diagnosis remains experimental but holds promise to increase future diagnostic capabilities in UTUC. Further large volume and prospective studies are still needed in order to determine the best means of noninvasive UTUC diagnosis.

\section{Acknowledgments}

Funding: None.

\section{Footnote}

Provenance and Peer Review: This article was commissioned by the Guest Editors (John J. Knoedler and Jay D. Raman) for the series "Upper-Tract Urothelial Carcinoma: Current State and Future Directions" published in Translational Andrology and Urology. The article was sent for external peer review organized by the Guest Editors and the editorial office.

Conflicts of Interest: All authors have completed the ICMJE uniform disclosure form (available at http:// dx.doi.org/10.21037/tau.2019.11.28). The series "UpperTract Urothelial Carcinoma: Current State and Future Directions" was commissioned by the editorial office without any funding or sponsorship. DHB is a consultant for Bard and Olympus/ACMI. The other authors have no other conflicts of interest to declare.

Ethical Statement: The authors are accountable for all aspects of the work in ensuring that questions related to the accuracy or integrity of any part of the work are appropriately investigated and resolved.

Open Access Statement: This is an Open Access article distributed in accordance with the Creative Commons Attribution-NonCommercial-NoDerivs 4.0 International License (CC BY-NC-ND 4.0), which permits the noncommercial replication and distribution of the article with the strict proviso that no changes or edits are made and the original work is properly cited (including links to both the formal publication through the relevant DOI and the license). See: https://creativecommons.org/licenses/by-nc-nd/4.0/.

\section{References}

1. Chlapoutakis K, Theocharopoulos N, Yarmentitis S, et al. Performance of computed tomographic urography in diagnosis of upper urinary tract urothelial carcinoma, in patients presenting with hematuria: Systematic review and meta-analysis. Eur J Radiol 2010;73:334-8.

2. Caoili EM, Cohan RH, Inampudi P, et al. MDCT urography of upper tract urothelial neoplasms. AJR Am J Roentgenol 2005;184:1873-81.

3. Rouprêt M, Babjuk M, Comperat E, et al. European Association of Urology Guidelines on Upper Urinary Tract Urothelial Carcinoma: 2017 update. Eur Urol 2018;73:111-22.

4. National Comprehensive Cancer Network Clinical Practice Guidelines in Oncology, Bladder Cancer. (Version 4.2019). Accessed 9.08.2019. Available online: https://www.nccn.org/professionals/physician_gls/pdf/ bladder.pdf

5. Keeley FX, Kulp DA, Bibbo M, et al. Diagnostic accuracy of ureteroscopic biopsy in upper tract transitional cell carcinoma. J Urol 1997;157:33-7.

6. Zheng X, Si Q, Du D, et al. The Paris System for urine cytology in upper tract urothelial specimens: A comparative analysis with biopsy and surgical resection. Cytopathology 2018;29:184-8.

7. McIntire PJ, Snow J, Robinson B, et al. Improved correlation of urinary cytology specimens using the Paris system in biopsy-proven upper tract urothelial carcinomas. Cancer Cytopathol 2018;126:498-504.

8. Vashistha V, Shabsigh A, Zynger D. Utility and diagnostic accuracy of ureteroscopic biopsy. Arch Pathol Lab Med 2013;137:400-7.

9. Potretzke AM, Knight BA, Potretzke TA, et al. Is ureteroscopy needed prior to nephroureterectomy? 
An evidence based algorithmic approach. Urology 2016;88:43-8.

10. Tawfiek E, Bibbo M, Bagley D. Ureteroscopic biopsy: technique and specimen preparation. Urology 1997;50:117-9.

11. Grasso M, Bagley DH. Upper Urinary Tract Urothelial Carcinoma. Switzerland: Springer, 2015.

12. Johnson GB, Portella D, Grasso M. Advanced Ureteroscopy: Wireless and Sheathless. J Endourol 2006;20:552-5.

13. Breda A, Territo A, Sanguedolce F, et al. Comparison of biopsy devices in upper tract urothelial carcinoma. World J Urol 2019;37:1899-905.

14. Lama DJ, Safiullah S, Patel R, et al. Multi-institutional evaluation of upper urinary tract biopsy using back loaded cup biopsy forceps, a nitinol basket, and standard cup biopsy forceps. Urology 2018;117:89-94.

15. Verges DP, Lallas CD, Hubosky SG, et al. Endoscopic treatment of upper tract urothelial carcinoma. Curr Urol Rep 2017;18:31.

16. Kleinmann N, Healy KA, Hubosky SG, et al. Ureteroscopic biopsy of upper tract urothelial carcinoma: comparison of basket and forceps. J Endourol 2013;27:1450-4.

17. Margolin EJ, Matulay JT, Gen L, et al. Discordance between ureteroscopic biopsy and final pathology for upper tract urothelial carcinoma. J Urol 2018;199:1440-5.

18. Huang SY, Ahrar K, Gupta S, et al. Safety and diagnostic accuracy of percutaneous biopsy in upper tract urothelial carcinoma. BJU Int 2015;115:625-32.

19. Sung HH, Jeon HG, Han DH, et al. Diagnostic ureteroscopy is associated with increased intravesical recurrence following radical nephroureterectomy in upper tract urothelial carcinoma. PLoS One 2015;10:e139976.

20. Lee HY, Yeh HC, Wu WJ, et al. The diagnostic ureteroscopy before radical nephroureterectomy in upper urinary tract urothelial carcinoma is not associated with higher intravesical recurrence. World J Surg Oncol 2018;16:135.

21. Guo RQ, Hong P, Xiong GY, et al. Impact of ureteroscopy before radical nephroureterectomy for upper tract urothelial carcinomas on oncological outcomes: a metaanalysis. BJU Int 2018;121:184-93.

22. Potretzke AM, Knight BA, Vetter JM, et al. Diagnostic utility of selective upper tract urinary cytology: A systematic review and meta-analysis of the literature.
Urology 2016;96:35-43.

23. Miyake M, Owari T, Hori S, et al. Emerging biomarkers for the diagnosis and monitoring of urothelial carcinoma. Res Rep Urol 2018;10:251-61.

24. Barkan GA, Wojcik EM, Nayar R, et al. The Paris System for reporting urinary cytology: the quest to develop a standardized terminology. Adv Anat Pathol 2016;23:193-201.

25. Xing J, Monaco SE, Pantanowitz L. Utility of the Paris system for reporting urinary cytology in upper tract specimens. J Am Soc Cytopathol 2018;7:311-7.

26. Simon CT, Skala SL, Magers MJ, et al. The utility of upper urinary tract cytology before and after application of the Paris system. Diagn Cytopathol 2019;47:421-7.

27. Sokolova IA, Halling KC, Jenkins RB et al. The development of a multitarget, multicolor florescence in situ hybridization assay for the detection of urothelial carcinoma in urine. J Mol Diagn 2000;2:116-23.

28. Johannes JR, Nelson E, Bibbo M. Voided urine fluorescence in situ hybridization testing for upper tract urothelial carcinoma surveillance. J Urol 2010;184:879-82.

29. Marín-Aguilera M, Mengual L, Ribal MJ, et al. Utility of fluorescence in situ hybridization as a non-invasive technique in the diagnosis of upper urinary tract urothelial carcinoma. Eur Urol 2007;51:409-15.

30. Monteiro-Reis S, Leca L, Almeida M, et al. Accurate detection of upper tract urothelial carcinoma in tissue and urine by means of quantitative GDF15, TMEFF2 and VIM promoter methylation. Eur J Cancer 2014;50:226-33.

31. Guo RQ, Xiong GY, Yang KW, et al. Detection of urothelial carcinoma, upper tract urothelial carcinoma, bladder carcinoma and urothelial carcinoma with gross hematuria using selected urine-DNA methylation biomarkers: A prospective, single center study. Urol Oncol 2018;36:342.e15-23.

32. Hayashi Y, Fujita K, Matsuzaki M, et al. Diagnostic potential of TERT promoter and FGFR3 mutations in urinary cell-free DNA in upper tract urothelial carcinoma. Cancer Sci 2019;110:1771-9.

Cite this article as: Smentkowski KE, Bagley DH, Hubosky SG. Ureteroscopic biopsy of upper tract urothelial carcinoma and role of urinary biomarkers. Transl Androl Urol 2020;9(4):1809-1814. doi: 10.21037/tau.2019.11.28 